\title{
The use of sugammadex in an infant with prolonged neuromuscular blockade - A case report -
}

\section{Hyunho Kim, Joonho Cho, Sangseok Lee, Yunhee Lim, and Byunghoon Yoo}

Department of Anesthesiology and Pain Medicine, Sanggye Paik Hospital, Inje University College of Medicine, Seoul, Korea
Received June 28, 2021

Revised August 2, 2021

Accepted August 6, 2021

\section{Corresponding author}

Byunghoon Yoo, M.D., Ph.D.

Department of Anesthesiology and Pain Medicine, Sanggye Paik Hospital, Inje University College of Medicine, 1342 Dongil-ro, Nowon-gu, Seoul 01757, Korea

Tel: 82-2-950-1172

Fax: 82-2-950-1323

E-mail: twowind@paik.ac.kr
Background: Residual neuromuscular blockade (RNMB) is a frequent event after general anesthesia, which can lead to serious complications, such as upper airway obstruction. Sugammadex is useful in reversing RNMB. However, its use in infants has not yet been approved by the Food and Drug Administration. Therefore, anesthesiologists can be hesitant use it, even in situations where no other choice is available.

Case: A two-month-old baby presented to the hospital for umbilical polypectomy. At the end of the surgery, neostigmine was administered. Even after waiting for $30 \mathrm{~min}$ and injecting an additional dose of neostigmine, neuromuscular blockade was not adequately reversed. Eventually, sugammadex was administered, and spontaneous breathing returned.

Conclusions: If there were no particular causes of delayed return to spontaneous breathing in infants, RNMB should be considered and reversal with sugammadex would be useful.

Keywords: Delayed emergence from anesthesia; Infant; Residual neuromuscular block; Rocuronium; Sugammadex.
If neuromuscular block is induced using a non-depolarizing neuromuscular blocking drug (NMBD) during general anesthesia, anticholinesterases such as neostigmine are used for reversal after surgery. However, even with the use of an appropriate dose of anticholinesterases, neuromuscular blockade is not always completely reversed, which can lead to residual neuromuscular blockade (RNMB) during the postoperative period. In such cases, spontaneous recovery of muscle power must be waited for [1]. Constant monitoring is required to detect the presence of RNMB. RNMB can lead to worsened breathing function, upper airway closure, or requirement of postoperative mechanical ventilation, which can have a significant impact on the patient's recovery $[2,3]$. In particular in children, RNMB was reported to occur in approximately $28.1 \%$ of general anesthesia cases [4].

Sugammadex was developed as a reversal agent for aminosteroid non-depolarizing NMBDs and has been widely used since its approval by the Food and Drug Administration (FDA) in 2015, and was approved by the Korean Ministry of Food and Drug Safety in 2012. Its mechanism of action involves a molecule of aminosteroid non-depolarizing NMBD being encircled in the lipophilic core region of sugammadex, preventing the molecule from binding to acetylcholine receptors at the neuromuscular junction [4]. This has the advantage of working faster than anticholinesterases by a different mechanism and significantly reducing the incidence of RNMB [5]. However, the use of sugammadex in children has not yet been approved by the FDA, and there is

This is an Open Access article distributed under the terms of the Creative Commons Attribution Non-Commercial License (http://creativecommons.org/licenses/by-nc/4.0) which permits unrestricted non-commercial use, distribution, and reproduction in any medium, provided the original work is properly cited.

Copyright (C) the Korean Society of Anesthesiologists, 2022 
a lack of research on establishing safety and effectiveness. Cases of safe use in children abroad and in Korea have been reported continuously $[6,7]$, but very less research data exist regarding its use in infants than that of children.

Herein, we report a case of reversal of neuromuscular blockade using sugammadex in a two-month-old infant with a review of the related literature.

\section{CASE REPORT}

Prior to the publication of this case, a written informed consent was obtained from the patient's parents.

A two-month-old infant presented to the hospital for umbilical polypectomy. He was born at a gestational age of $38^{+1}$ weeks, weighing $2.99 \mathrm{~kg}$, and had no particular features other than a mass protruding from the navel. Under the diagnosis of umbilical granuloma, cautery using $\mathrm{AgNO}_{3}$ was performed twice in the clinic, but no improvement was observed.

After admission, vital signs were normal, and the weight was measured at $5.4 \mathrm{~kg}$, and laboratory tests showed no abnormalities. When visited for preoperative evaluation before surgery, the patient was active and showed no signs of decreased muscle tone. As a premedication, intramuscular atropine $0.1 \mathrm{mg}$ was administered. The patient was closely monitored using electrocardiography, pulse oximetry, and esophageal body temperature during surgery. The patient's heart rate exceeded the normal range, probably due to dehydration or the effect of premedication with atropine. After intravenous administration of thiopental $25 \mathrm{mg}$, mask ventilation was performed out using sevoflurane, followed by intravenous injection of rocuronium $3 \mathrm{mg}$. Mask ventilation was not difficult, and endotracheal intubation was performed using a direct laryngoscope. During endotracheal intubation, the airway view was well secured as Cormack-
Lehane grade 1, and intubation was successful using an endotracheal tube without cuff with an internal diameter of 3.0. General anesthesia was maintained using sevoflurane, $\mathrm{O}_{2}$, and $\mathrm{N}_{2} \mathrm{O}$ (Table 1). Using a forced air warming system, the body temperature was maintained within the normal range.

The operation took $42 \mathrm{~min}$. At the end of the surgery, the train-of-four (TOF) count was expected to be at least 3 , as inferred from the clinical duration of rocuronium. Although neuromuscular monitoring should have been used, considering the clinical effects of the drug, the authors decided to administer the reversal agent empirically. Neostigmine 0.25 mg was intravenously administered to reverse neuromuscular blockade at the end of the surgery. The patient was manually ventilated, and the authors waited for a return to spontaneous breathing. However, recovery was not observed even approximately 35 min after neostigmine administration. Dose of anticholinesterase needed to reverse neuromuscular blockade is $0.07 \mathrm{mg} / \mathrm{kg}$ at TOF count $2-3$. An additional dose of neostigmine was administered under the suspicion of a lack of adequate dose of reversal agent.

The continued effect of atropine given by premedication was expected considering patient's heart rate, so instead of administering neostigmine/glycopyrrolate mixture, we planned to administer neostigmine firstly and monitor changes in EKG, heart rate, then secondly administer glycopyrrolate. Heart rate and EKG remained stable after the sole administration of neostigmine. The pupil reflex was normal, but spontaneous respiration did not return. Approximately $30 \mathrm{~min}$ after the second dose of neostigmine (approximately $1 \mathrm{~h}$ after the first dose of neostigmine), the post-tetanic count (PTC) of 0 was measured using a neuromuscular monitoring device (TOF-Watch, Organon Ltd., Ireland). Manual ventilation was maintained for approximately 20 min, and the PTC of 2 was measured. Sugammadex $25 \mathrm{mg}$ was administered because it was determined that reversal of

Table 1. Pre- and Intra-operative Vital Sign and Administered General Anesthetics

\begin{tabular}{|c|c|c|c|c|c|c|c|c|}
\hline Time & $\begin{array}{l}\text { Heart rate } \\
\text { (beats/min) }\end{array}$ & $\begin{array}{l}\text { Respiratory rate } \\
\text { (breaths/min) }\end{array}$ & $\begin{array}{c}\mathrm{ETCO}_{2} \\
(\mathrm{mmHg})\end{array}$ & $\mathrm{SpO}_{2}(\%)$ & Tidal volume (ml) & $\begin{array}{l}\text { Sevoflurane } \\
\text { (vol \%) }\end{array}$ & $\begin{array}{l}\mathrm{O}_{2}: \mathrm{N}_{2} \mathrm{O} \\
(\mathrm{L} / \mathrm{min})\end{array}$ & Note \\
\hline $12: 45$ & 210 & 23 & & 100 & & & & \\
\hline 12:47 & 202 & 28 & & 100 & & & $5: 0$ & $\begin{array}{l}\text { Thiopental } \\
25 \text { mg IV }\end{array}$ \\
\hline $12: 48$ & 194 & 25 & & 100 & & 4 & $5: 0$ & $\begin{array}{l}\text { Rocuronium } \\
3 \mathrm{mg} \mathrm{IV}\end{array}$ \\
\hline 13:00 & 200 & 22 & & 100 & 40 & 2.5 & $1.5: 1.5$ & $36.8^{\circ} \mathrm{C}$ \\
\hline 13:03 & 197 & 20 & 36 & 100 & 40 & 2.5 & $1.5: 1.5$ & Incision \\
\hline $13: 45$ & 188 & 22 & 32 & 100 & 35 & 2.5 & $1.5: 1.5$ & End of surgery \\
\hline
\end{tabular}

$\mathrm{ETCO}_{2}$ : end-tidal $\mathrm{CO}_{2}, \mathrm{SpO}_{2}$ : saturation of percutaneous oxygen, IV: intravenous. 
neuromuscular blockage was incomplete. After administration of sugammadex, the patient began to move slightly, measuring up to $77 \%$ of the TOF ratio, with recovery of spontaneous respiration (Table 2, Fig. 1). The TOF was > 90\% at the time of extubation. The patient was transported to the post-anesthesia care unit (PACU) thereafter.

After arriving at the PACU, $5 \mathrm{~L} / \mathrm{min}$ of $\mathrm{O}_{2}$ was administered through a mask with a reservoir bag for $20 \mathrm{~min}$, and oxygen saturation was between $98 \%$ and $100 \%$. The patient stayed in the PACU for about 50 min and was transferred to the ward without any problems. In the ward, an antipyretic was prescribed because of the high body temperature of $38^{\circ} \mathrm{C}$ the day after the surgery, and he was discharged after the fever subsided. The surgical site was observed to be clean five days after the discharge. The patient was active, and no specific neurological symptoms were observed.

\section{DISCUSSION}

As children are immature in the development of neuro-

Table 2. Postoperative Anesthesia Recovery Progress after Administration of Neostigmine and Sugammadex

\begin{tabular}{|c|c|c|c|c|c|c|}
\hline Time & $\begin{array}{l}\text { Time elapsed since the first } \\
\text { injection of reverse medication }\end{array}$ & IV drug & Dose & $\begin{array}{c}\text { Neuromuscular } \\
\text { blockade monitoring }\end{array}$ & BT & Note \\
\hline $13: 42$ & & Neostigmine & $0.25 \mathrm{mg}$ & & & \\
\hline $14: 18$ & $36 \mathrm{~min}$ & Neostigmine & $0.25 \mathrm{mg}$ & & & \\
\hline $14: 45$ & $1 \mathrm{~h} 3 \mathrm{~min}$ & & & PTC 0 & & \\
\hline $15: 05$ & $1 \mathrm{~h} 23 \mathrm{~min}$ & & & PTC 2 & $35.9^{\circ} \mathrm{C}$ & \\
\hline 15:06 & & & & & & $\begin{array}{l}\text { Forced } \\
\text { air warming }\end{array}$ \\
\hline $15: 11$ & $1 \mathrm{~h} 29 \mathrm{~min}$ & Sugammadex & $25 \mathrm{mg}$ & TOF 0 & & \\
\hline $15: 12$ & & & & TOF 2 & & \\
\hline $15: 13$ & & & & TOF 4 & & \\
\hline $15: 14$ & & & & TOF $74 \%$ & & \\
\hline $15: 15$ & $1 \mathrm{~h} 33 \mathrm{~min}$ & & & TOF $77 \%$ & $36.3^{\circ} \mathrm{C}$ & Extubation ${ }^{*}$ \\
\hline
\end{tabular}

BT: body temperature, IV: intravenous, EMR: electronic medical record, TOF: train-of-four, PTC: post-tetanic count. *Due to the limitations of the EMR system, the last TOF ratio recorded was $77 \%$, but actual extubation was performed after confirming that the TOF ratio was $95 \%$.
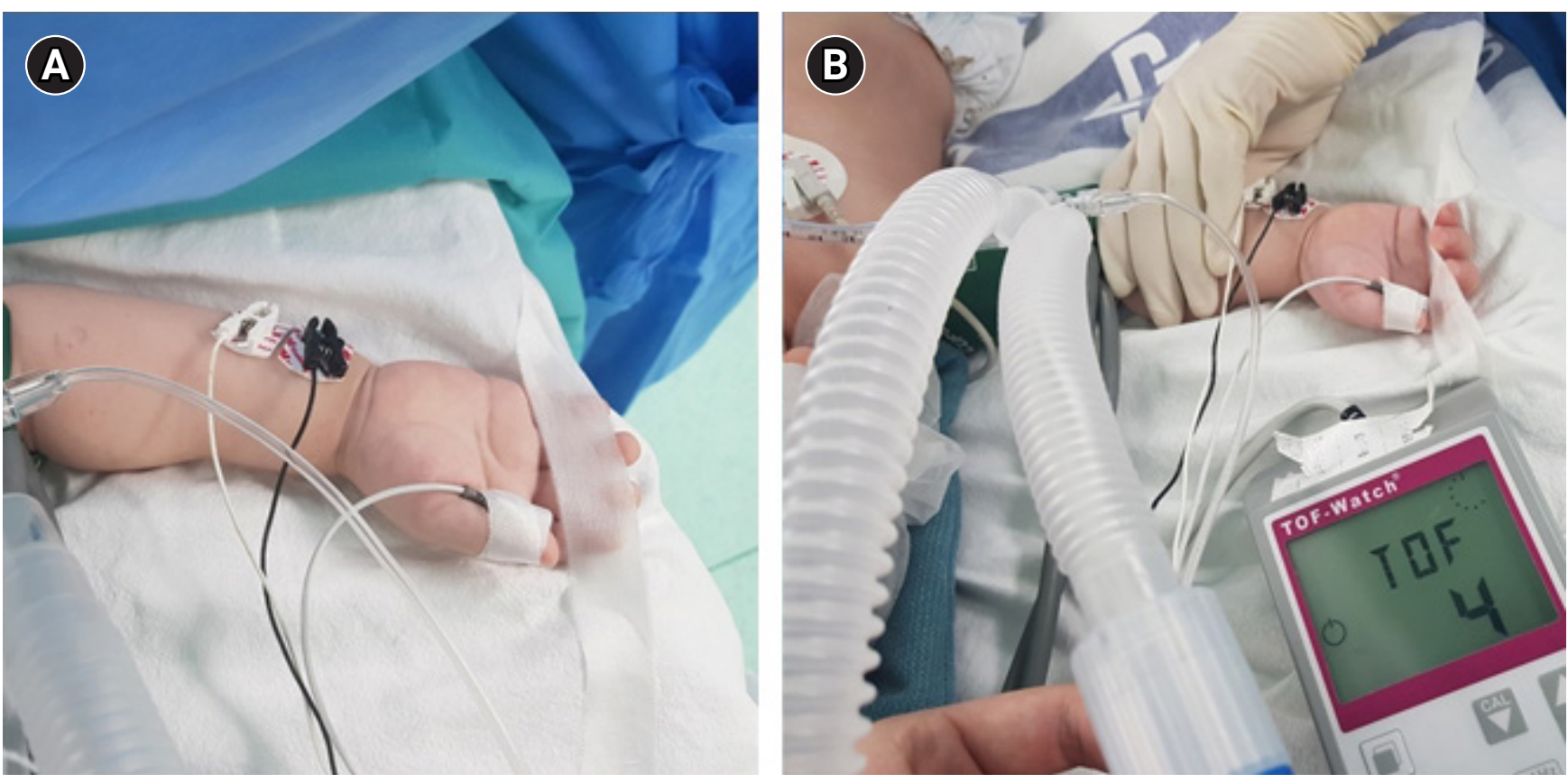

Fig. 1. The monitoring device was attached on the patient's arm. (A) The size of lead for stimulation was inappropriate for an infant, so the edge was cut and used. (B) Neuromuscular blockade reversed as TOF 4 after administration of sugammadex. TOF: train-of-four. 
muscular junctions and differ in pharmacokinetics of drugs from adults, caution is needed when using a variety of drugs, including NMBDs and their reversal agents. In particular, the effective use of NMBDs in acetylcholine receptors in infants and acetylcholine deficiency in their developing motor nerves may make them vulnerable to the action of a non-depolarizing NMBD $[1,8]$. This delays recovery from neuromuscular blockade and increases the risk of RNMB after surgery. Therefore, for general anesthesia, it is desirable to confirm the TOF ratio before and after the administration of NMBDs and its reversal agent.

Recently, there have been continuous reports of reversal of neuromuscular blockade without adverse events by administering sugammadex in pediatric patients diagnosed with genetic disease accompanied by decreased muscle tone. Kim and Chun [9] used $2 \mathrm{mg} / \mathrm{kg}$ of sugammadex in an 11-year-old child diagnosed with Duchenne muscular dystrophy. Sung et al. [10] also used $2 \mathrm{mg} / \mathrm{kg}$ of sugammadex in a 4-year-old child diagnosed with Prader-Willi syndrome. In both cases, the neuromuscular blockade was effectively reversed without any side effects.

In addition, the number of cases of sugammadex use in infants is increasing. Franz et al. [11] recently reported 331 cases of sugammadex used in infants under 2-year-olds. According to the report, $2 \mathrm{mg} / \mathrm{kg}$ of sugammadex for 223 cases, $4 \mathrm{mg} / \mathrm{kg}$ for 98 cases, and $16 \mathrm{mg} / \mathrm{kg}$ for 10 cases were used, with no notable adverse events. However, the use of sugammadex has only been approved in adults. Therefore, anesthesiologists cannot help hesitating regarding using it in infants.

In this case, the patient was not diagnosed with any genetic disease accompanied by decreased muscle tone or abnormal liver or kidney function. Therefore, other causes had to be identified initially before determining that the cause of delayed recovery was due to RNMB. Delayed recovery from anesthesia has a variety of causes, including pharmacokinetics, pharmacodynamics, and neurological reasons [12]. Firstly, cerebral ischemia was considered, the most likely neurological reason. However, there was no history of cerebrovascular disease and no special events during surgery to suspect air embolism, and relatively stable vital signs were maintained and pupil reflexes were intact; thus, neurological causes were excluded. In addition, the end-tidal concentration of sevoflurane gas was reduced to less than $0.1 \%$ at the time of arousal, and opioids were not used; therefore, excessive sedation was ruled out. To prevent hypoxia and hypothermia, which can affect the recovery of spontaneous respiration, the end-tidal carbon dioxide $\left(\mathrm{ETCO}_{2}\right)$ was maintained between 35 and $40 \mathrm{mmHg}$, and the normal body temperature was maintained by applying a forced air warmer. Finally, RNMB was identified by monitoring the TOF ratio, and recovery was achieved without adverse effects using sugammadex.

PTC of 2, even with administration of a neuromuscular blockade reversal agent, can be caused by a variety of causes. First, a residual neuromuscular blockade was considered. The criteria for appropriate reversal of neuromuscular blockade is 0.90 or higher on TOF monitoring. Although PTC of 2 is of unclear cause, it can be determined that it was caused by insufficient reversal of neuromuscular blockade. The factors that can cause insufficient reversal can be divided into three categories: pre-, intra-, and post-operative. Preoperative factors include patient's age, sex, preoperative conditions, and medications that can affect neuromuscular transmission. The most likely explanation for this case was age. Anderson reported that the effectiveness of NMBD increases in neonates because of altered pharmacodynamics [13]. The type of NMBD could be considered as an intraoperative factor. Rocuronium was used as an intermediate-acting drug, but the dose was not excessive. Although electrolyte imbalance could not be confirmed intraoperatively, preoperative laboratory tests showed normal electrolyte levels. Moreover, there were few factors that could affect the patient's general status during surgery, so electrolyte imbalance could be excluded. The inhaled anesthetics could affect the effect of neuromuscular blockade, but most anesthetics were removed because sufficient time had passed. Hypothermia could be considered a postoperative factor, but it did not occur in this case.

Second, neostigmine-induced muscle weakness could be considered as the cause of PTC of 2. Neostigmine administration after complete reversal of neuromuscular blockade potentially has a negative effect on respiratory muscles. Changed sensitivity of the upper airway muscles in the presence of overabundant acetylcholine can lead to desensitization of the acetylcholine receptor, depolarizing blockade, or an open channel blockade [4]. Neostigmine-induced muscle weakness could be ruled out because neuromuscular blockade was reversed immediately after administration of sugammadex. Comprehensively, the most likely factor for this case was the extension of the neuromuscular blockade duration due to age.

In this case, using sugammadex seems appropriate to complete insufficient reversal of neuromuscular blockade. 
Moreover, it is very important to monitor neuromuscular blockade before induction of anesthesia in infants as well as in all patients.

After the surgery, the patient and patient's parents were interviewed to check for further medical and family history, and there were no specifics other than hypertension on the paternal side. However, there is a possibility that the patient may have had an undiagnosed genetic condition associated with neuromuscular junctions, such as congenital myasthenic syndrome. The parents were given an explanation that the patient may experience a delayed recovery from general anesthesia again in the future.

In conclusion, RNMB can occur in anyone, and a present, waiting for spontaneous respiration recovery is the usual option to manage it. In case of an incomplete recovery even after waiting, a decision to wait more or to give sugammadex for full recovery needs to be made. Although the use of sugammadex in children has not yet been approved by the FDA, according to continuously reported studies, the use of sugammadex at $2-4 \mathrm{mg} / \mathrm{kg}$ is reasonable considering the risk caused by RNMB.

\section{FUNDING}

None.

\section{CONFLICTS OF INTEREST}

No potential conflict of interest relevant to this article was reported.

\section{DATA AVAILABILITY STATEMENT}

Not applicable.

\section{AUTHOR CONTRIBUTIONS}

Conceptualization: Hyunho Kim, Byunghoon Yoo. Writing - original draft: Hyunho Kim. Writing - review \& editing: Hyunho Kim, Joonho Cho, Sangseok Lee, Yunhee Lim, Byunghoon Yoo. Supervision: Sangseok Lee, Byunghoon Yoo. Validation: Byunghoon Yoo.

\section{ORCID}

Hyunho Kim, https://orcid.org/0000-0002-8954-5431

Joonho Cho, https://orcid.org/0000-0002-9693-8057
Sangseok Lee, https://orcid.org/0000-0001-7023-3668

Yunhee Lim, https://orcid.org/0000-0003-2399-4768

Byunghoon Yoo, https://orcid.org/0000-0002-1958-8380

\section{REFERENCES}

1. Meretoja OA. Neuromuscular block and current treatment strategies for its reversal in children. Paediatr Anaesth 2010; 20: 591-604.

2. Viby-Mogensen J, Jørgensen BC, Ording H. Residual curarization in the recovery room. Anesthesiology 1979; 50: 539-41.

3. Viby-Mogensen J. Postoperative residual curarization and evidence-based anaesthesia. Br J Anaesth 2000; 84: 301-3.

4. Gropper MA, Eriksson LI, Fleisher LA, Wiener-Kronish JP, Cohen NH, Leslie K. Miller's anesthesia. 9th ed. Philadelphia, Elsevier. 2020. p. 832-64.

5. Jones RK, Caldwell JE, Brull SJ, Soto RG. Reversal of profound rocuronium-induced blockade with sugammadex: a randomized comparison with neostigmine. Anesthesiology 2008; 109: 816-24.

6. Tobias JD. Current evidence for the use of sugammadex in children. Paediatr Anaesth 2017; 27: 781

7. Won YJ, Lim BG, Lee DK, Kim H, Kong MH, Lee IO. Sugammadex for reversal of rocuronium-induced neuromuscular blockade in pediatric patients: a systematic review and meta-analysis. Medicine (Baltimore) 2016; 95: e4678.

8. Ozmete O, Bali C, Cok OY, Turk HE, Ozyilkan NB, Civi S, et al. Sugammadex given for rocuronium-induced neuromuscular blockade in infants: a retrospectıve study. J Clin Anesth 2016; 35: 497-501

9. Kim JE, Chun HR. Rocuronium-induced neuromuscular block and sugammadex in pediatric patient with duchenne muscular dystrophy: a case report. Medicine (Baltimore) 2017; 96: e6456.

10. Sung TY, Kang T, Cho C, Kwon HU, Kang PS, Jee YS. Experience with reversal of a neuromuscular block with sugammadex in a child with Prader-Willi syndrome - a case report -. Anesth Pain Med 2017; 12: 335-8.

11. Franz AM, Chiem J, Martin LD, Rampersad S, Phillips J, Grigg EB. Case series of 331 cases of sugammadex compared to neostigmine in patients under 2 years of age. Paediatr Anaesth 2019; 29: 591-6

12. Cascella M, Bimonte S, Di Napoli R. Delayed emergence from anesthesia: what we know and how we act. Local Reg Anesth 2020; 13: 195-206.

13. Anderson BJ. Pharmacology in the very young: anaesthetic implications. Eur J Anaesthesiol 2012; 29: 261-70. 